\title{
Jiří Kejř, Die mittelalterlichen Städte in den böhmischen Ländern, Gründung - Verfassung - Entwicklung
}

(traduit du tchèque par Hildegard Bobková et Václav Bok, Städteforschung, Reihe A: Darstellungen, Band 78) Köln Weimar Wien : Böhlau, , 2010, 450 p

\section{Éloïse Adde}

\section{OpenEdition}

\section{Journals}

Édition électronique

URL : http://journals.openedition.org/ifha/8211

DOI : 10.4000/ifha.8211

ISSN : 2198-8943

Éditeur

IFRA - Institut franco-allemand (sciences historiques et sociales)

\section{Référence électronique}

Éloïse Adde, « Jiří Kejřr, Die mittelalterlichen Städte in den böhmischen Ländern, Gründung - Verfassung Entwicklung », Revue de l'IFHA [En ligne], Date de recension, mis en ligne le 14 avril 2015, consulté le 22 septembre 2020. URL : http://journals.openedition.org/ifha/8211 ; DOI : https://doi.org/10.4000/ifha. 8211

Ce document a été généré automatiquement le 22 septembre 2020.

(C)IFHA 


\section{Jiří Kejřr, Die mittelalterlichen Städte in den böhmischen Ländern, Gründung - Verfassung - Entwicklung}

(traduit du tchèque par Hildegard Bobková et Václav Bok, Städteforschung, Reihe A: Darstellungen, Band 78) Köln Weimar Wien : Böhlau, , 2010, 450 p

\section{Éloïse Adde}

Publié en tchèque sous le titre originel Vznik městského zřízení v českých zemích aux éditions Karolinum en 1998, cet ouvrage constitue la synthèse incontournable pour qui s'intéresse à l'histoire des villes de la Bohême médiévale. Juriste de formation, Jiřri Kejř s'est ensuite spécialisé dans l'histoire du droit, en particulier celles des institutions urbaines médiévales et c'est une véritable somme qu'il nous propose avec cet ouvrage, que l'on se félicite de voir traduit dans une langue plus accessible que le tchèque sur l'initiative de Peter Johanek, le directeur de la collection 'Städteforschung'.

Exhaustif, l'ouvrage revient sur l'apparition et le développement des institutions municipales dans les pays tchèques, sur l'intérêt des souverains přemyslides pour l'apparition d'un réseau urbain et sur l'impact du phénomène sur la composition de la société. Se voulant le plus complet possible, il recouvre l'ensemble des pays de la couronne de Bohême, à savoir : la Bohême, la Moravie, la Silésie autrichienne, la haute et la basse Lusace et le comté de Kłodzko (Glatz). À sa sortie, le volume avait été ovationné en République tchèque pour la richesse de l'appareil documentaire et des sources juridiques et diplomatiques $\mathrm{du}$ XIIIe siècle prises en compte. Le volume se divise en dix sections. Après une première partie présentant l'état de la recherche tchèque sur la ville comme objet scientifique (p. 7-52) et une digression concernant les villes dans les documents de l'époque přemyslide (p.53-78), J. Kejř fait un sort tout particulier aux questions de terminologie (p. 79-144), s'employant à recenser et définir les différents types de peuplement urbain (villa, vicus, locus, etc.) ainsi que les personnes (civis, burgensis, habitator, etc.), tels qu'il les rencontre dans les sources, faisant un sort particulier aux expressions allemandes (p. 143-144), pour ensuite se 
consacrer à l'acte fondateur de la ville (partie III, p. 145-175), au droit urbain (partie IV, p. 176-233), aux aspects économiques (partie V sur la prospérité économique assurée par la ville et partie VI sur l'apparition d'un marché, p. 234-298), à l'administration (partie VII, p. 299-337), à la justice urbaine (partie VIII, p. 338-351), aux ordres mendiants (partie IX, p. 352-362) et, pour finir, à la bourgeoisie (partie X, p. 363-407). Proche du catalogue et donc dénuée de visée conceptuelle novatrice, l'ouvrage pèche encore par l'absence d'une démarche réellement pluridisciplinaire. Bien qu'il vante luimême les mérites du recours à l'archéologie, l'auteur fait en réalité un usage plus que parcimonieux des avancées de cette discipline pourtant essentielle pour mieux connaître la ville médiévale, comme l'ont régulièrement montré les travaux de Jan Klapště. Cette synthèse n'en est pas moins la plus complète dans le domaine. En outre, son travail minutieux sur les sources conduit Jiř́ Kejř à mettre fin à certaines idées reçues: si rien n'atteste la diffusion du droit de Nuremberg dans les villes tchèques contrairement à ce qui était prétendu jusqu'alors, le droit de Magdebourg se serait lui imposé dans certaines villes de Moravie du Nord à partir du XIVe siècle.

Saluons, pour conclure, la grande qualité de la traduction ainsi livrée, réalisée par les soins de Václav Bok et de sa défunte épouse, Hildegard Boková, germanistes spécialisés en études médiévales de l'université de České Budějovice.

\section{INDEX}

Index chronologique : Moyen Âge

Thèmes : Histoire des villes et des régions, Histoire du droit

\section{AUTEUR}

\section{ÉLOÏSE ADDE}

Université de Luxembourg 